\title{
A influência do tipo de parto no desmame precoce
}

\author{
The influence of the type of delivery on early weaning
}

\author{
La influencia del tipo de parto en el destete temprano
}

\section{Anna Carolina Lomelino Lemos Medeiros ${ }^{1 *}$, Geisa Sereno Velloso da Silva ${ }^{2}$, Elisângela Nascimento Fernandes Gomes 3 , Jannaina Sther Leite Godinho Silva ${ }^{4}$, Alessandra da Silva Souza ${ }^{5}$, Eliara Adelino da Silva ${ }^{6}$ \\ Como citar esse artigo. Medeiros, \\ Resumo} ACLL; da Silva, GSV; Gomes, NF; Silva, JSLG; Souza, AS; da Silva, EA. A influência do tipo de parto no desmame precoce. Revista Pró-UniverSUS. 2021 Jul./Dez.; 12 (2)SUPLEMENTO: 72 78.

Objetivo: Analisar a relação do tipo de parto e sua influência sobre o desmame precoce. Materiais e Métodos: Trata-se de uma pesquisa exploratória e descritiva, de cunho bibliográfico e abordagem quanti-qualitativa, tendo como fontes de pesquisa as seguintes bases de dados: LILACS e BDENF. Resultados: A partir da busca nas bases de dados foi possível identificar três categorias: O Aleitamento Materno Exclusivo (AME); leis e políticas públicas que amparam o aleitamento materno no Brasil e por último, a influência do tipo de parto sobre o desmame precoce. Discussão: $\mathrm{O}$ leite materno é considerado o alimento ideal para a saúde, o desenvolvimento e crescimento do bebê, além do fortalecimento de seu vínculo afetivo com a mãe, fornecendo proteção, nutrição e vantagens imunológicas à criança, contribuindo para a redução da morbimortalidade infantil. Por isso, leis e políticas públicas foram delimitadas para que esse processo pudesse ser fortalecido. No entanto, a taxa de desmame precoce no país ainda se encontra alta. Conclusão: $\mathrm{O}$ desmame precoce sofre forte influência por conta do tipo de parto, em especial a cesárea, que reduz pela metade a prevalência da amamentação na primeira hora de vida por conta do efeito da anestesia e dos cuidados no pós-operatório, aumentando o tempo de contato entre mãe e filho.

Palavras-chave: Desmame Precoce; Aleitamento Materno; Aleitamento Materno Exclusivo.

\begin{abstract}
Objective: To analyze the relationship between the type of delivery and its influence on early weaning. Materials and Methods: This is an exploratory and descriptive research, of bibliographic nature and quantitative and qualitative approach, having as sources of research the following databases: LILACS and BDENF. Results: From the search in the databases, it was possible to identify three categories: Exclusive Breastfeeding (EBF); public laws and policies that support breastfeeding in Brazil and, finally, the influence of the type of delivery on early weaning. Discussion: Breast milk is considered the ideal food for the baby's health, development and growth, in addition to strengthening its affective bond with the mother, providing protection, nutrition and immunological advantages to the child, contributing to the reduction of infant morbidity and mortality. Therefore, laws and public policies were delimited so that this process could be strengthened. However, the rate of early weaning in the country is still high. Conclusion: Early weaning is strongly influenced by the type of delivery, especially cesarean section, which halves the prevalence of breastfeeding in the first hour of life due to the effect of anesthesia and care in the postoperative period, increasing the time of contact between mother and child.
\end{abstract}

Keywords: Early Weaning; Breastfeeding; Exclusive Breastfeeding.

Afiliação dos autores: ${ }^{1 *}$ Acadêmica do Curso de Enfermagem da Universidade de Vassouras, Vassouras, RJ, Brasil. ORCID: https://orcid.org/0000-0002-8835-9389 2 Mestre em Enfermagem pela UFRJ, Docente do Curso de Enfermagem da Universidade de Vassouras, Vassouras, RJ, Brasil. ORCID: https://orcid.org/0000-0003-0304-8010. ${ }^{3}$ Mestre em Ciências Ambientais pela Universidade de Vassouras, Docente do Curso de Enfermagem da Universidade de Vassouras, Vassouras, RJ, Brasil. ORCID: http://orcid. org/0000-0001-8432-4157

${ }^{4}$ Mestre em Enfermagem pela Universidade Federal Fluminense, Docente do Curso de Enfermagem da Universidade de Vassouras. Vassouras, RJ, Brasil. ORCID: https://orcid. org/0000-0002-8308-2093

${ }^{5}$ Mestre em Ciências Ambientais pela Universidade de Vassouras, Docente do Curso de Enfermagem da Universidade de Vassouras, Vassouras, RJ, Brasil. ORCID: https://orcid. org/0000-0002-9009-9774.

${ }^{6}$ Mestre em Ciências da Saúde e Meio Ambiente, Docente do Curso de Enfermagem da Universidade de Vassouras, Vassouras, RJ, Brasil. ORCID: https://orcid.org/0000-0003-43876662.

* Email de correspondencia: carolinalomelino@outlook.com

Recebido em: 13/01/21. Aceito em: 18/05/21. 


\section{Resumen}

Objetivo: Analizar la relación entre el tipo de parto y su influencia en el destete precoz. Materiales y Métodos: Se trata de una investigación exploratoria y descriptiva, de carácter bibliográfico y abordaje cuantitativo y cualitativo, teniendo como fuentes de investigación las siguientes bases de datos: LILACS y BDENF. Resultados: A partir de la búsqueda en las bases de datos, fue posible identificar tres categorías: Lactancia Materna Exclusiva (LME); leyes y políticas públicas que apoyan la lactancia materna en Brasil y, finalmente, la influencia del tipo de parto en el destete temprano. Discusión: La leche materna es considerada el alimento ideal para la salud, desarrollo y crecimiento del bebé, además de fortalecer su vínculo afectivo con la madre, brindando protección, nutrición y ventajas inmunológicas al niño, contribuyendo a la reducción de la morbimortalidad infantil. Por lo tanto, se delimitaron leyes y políticas públicas para que este proceso se fortaleciera. Sin embargo, la tasa de destete temprano en el país sigue siendo alta. Conclusión: El destete precoz está fuertemente influenciado por el tipo de parto, especialmente la cesárea, que reduce a la mitad la prevalencia de la lactancia materna en la primera hora de vida por efecto de la anestesia y los cuidados en el postoperatorio, aumentando el tiempo de contacto entre madre e hijo.

Palabras clave: Destete Precoz; Lactancia Materna; Lactancia Materna Exclusiva.

\section{Introdução}

De acordo com a Organização Mundial da Saúde (OMS), o Aleitamento Materno Exclusivo (AME) diz respeito ao leite materno sendo a única e exclusiva alimentação do bebê recomendada até os seis meses de vida, direto da mama ou ordenhado, ou leite humano de outra fonte, sem introduzir nenhum outro alimento líquido ou sólido, com exceção dos medicamentos em forma de gotas ou xaropes contendo suplementos de vitaminas e minerais ou sais de reidratação oral, apenas quando recomendados pelo médico, seguindo assim, uma forma de amamentação complementada após os seis meses e até os dois anos de idade ou mais. ${ }^{1}$

O AME proporciona diversos benefícios, no entanto, ainda continua sendo um desafio, já que sua prevalência em várias regiões do país continua abaixo do estipulado pela OMS e pelo Ministério da Saúde (MS) que estabelecem $100 \%$ até os seis meses de vida. ${ }^{2}$

$\mathrm{O}$ aleitamento materno tem sido um dos assuntos maisdiscutidosdentrodaSaúdedaMulher,principalmente por apresentar fatores que estão intimamente ligados ao desenvolvimento da criança e o fortalecimento de seu vínculo afetivo com a mãe, especialmente nos primeiros dias de vida. O AME proporciona um impacto positivo sobre a saúde e o desenvolvimento e crescimento do bebê, e ainda, fornecendo proteção, nutrição e vantagens imunológicas à criança, contribuindo para a redução da morbimortalidade infantil. ${ }^{3,4}$

Cabe ressaltar, que a amamentação proporciona vantagens não apenas ao bebê, como à mãe também. Aponta-se, que o aleitamento materno para a nutriz é capaz de diminuir certos tipos de fraturas ósseas, câncer de mama e de ovários, além de reduzir o risco de morte por artrite reumatoide. ${ }^{5}$

O AME é indicado até os seis primeiros meses de vida da criança, e é reconhecido mundialmente como instrumento potencializador de vários benefícios, como a prevenção de infecções gastrintestinais, respiratórias e urinárias. E ainda, a longo prazo, a importância do aleitamento materno na prevenção do diabetes mellitus e de linfomas.6 Após o período de seis meses de vida indicado para o aleitamento materno, o ideal é que a amamentação seja completada até os dois anos ou mais.

No entanto, no processo de amamentação, no que diz respeito ao seu tempo de duração, este pode ser influenciado por diversos fatores, dentre eles, complicações referentes à assistência ao parto, baixo peso ao nascer, déficit de orientação ao aleitamento no hospital e cuidados oferecidos ao recém-nascido, resultando no aumento da ocorrência do desmame precoce. $^{4}$

Assim, o desmame precoce pode ser resultado do tipo de parto utilizado, comprometendo a realização do aleitamento materno. O parto normal é capaz de fortalecer o vínculo afetivo entre mãe e filho, promovendo a excreta de leite, condição favorável para a amamentação. A cesárea, por sua vez, determina um tempo maior para o contato afetivo, acarretando no início tardio da amamentação e a consequente interrupção precoce do aleitamento materno, referente à incisão e os efeitos da anestesia no pós-parto. ${ }^{4}$

Diante disso, destaca-se como objeto de estudo, a análise da influência do tipo de parto com o desmame precoce, e definindo-se como questão norteadora: De que forma o tipo de parto pode influenciar no aleitamento materno?

Assim, o trabalho foi desenvolvido a partir de uma pesquisa exploratória e descritiva, de cunho bibliográfico e abordagem quanti-qualitativa, tendo como fontes de pesquisa, as seguintes bases de dados: LILACS e BDENF, considerando ainda, fontes como trabalhos acadêmicos (monografias, especializações e mestrados), e a legislação e políticas públicas que envolvem o aleitamento materno no Brasil.

No entanto, o material encontrado que faz alusão direta com o tema, apresentou uma escassez de obras 
literárias, sendo pertinente a discussão de fatores que estivessem associados ao tema, justificando, portanto, a escolha do assunto abordado, que consiste em colocar em pauta a defesa por maior visibilidade do assunto.

$\mathrm{O}$ que se busca aqui, é poder contribuir com estudos e trabalhos futuros no campo da Saúde da Mulher, propagar mais informações e a produção de conhecimentos acerca do aleitamento materno e sua problemática, o desmame precoce e a influência do tipo de parto.

Nessa perspectiva, foi delimitado como objetivo principal deste trabalho: a discussão sobre a influência do tipo de parto e sua relação com o desmame precoce, impactos e fatores associados. E, por sua vez, apontados como objetivos específicos: Apresentar os benefícios e propriedades do aleitamento materno; estudar sobre as políticas públicas e leis que regem o aleitamento materno e contribuir com a propagação de informações e produção de conhecimento a respeito da Saúde da Mulher no que tange o desmame precoce sob influência do parto.

\section{Metodologia}

O estudo em questão foi desenvolvido a partir de uma pesquisa exploratória e descritiva e de âmbito bibliográfica.Apartirdisso, para efetivação da discussão acerca do tema, foi feito um levantamento de dados através da BVS (Biblioteca Virtual em Saúde), levando em consideração a abordagem quanti-qualitativa, e tendo como fontes de pesquisa as seguintes bases de dados: LILACS e BDENF, considerando ainda, fontes como trabalhos acadêmicos (monografias, especializações e mestrados), e a legislação brasileira e políticas públicas que envolvam o aleitamento materno.

A princípio, foi realizada uma busca bibliográfica através dos destinatários nas bases de dados: "desmame precoce", "aleitamento materno" e "aleitamento materno exclusivo", utilizando as seguintes combinações: aleitamento materno e desmame precoce; desmame precoce e tipo de parto; aleitamento materno exclusivo e desmame precoce. Diante disso, o material encontrado foi analisado a partir do título de cada artigo, em seguida, o resumo e a Introdução.

A busca pelos artigos e a construção do trabalho foram feitas no período de março a setembro de 2020. Foram encontrados 412 artigos relacionados aos assuntos secundários ao tema, e foram selecionados para o desenvolvimento dos resultados e discussão do trabalho 10 artigos, com um espaço temporal entre os anos de 2013 a 2020. Em se tratando do assunto direto ao tema em questão, foram encontrados apenas dois artigos, na base de dados BDENF.

Com a busca foi possível perceber a baixa produção quase inexistente de artigos que guardavam relação direta do tipo de parto com o desmame precoce, o que acarretou em mais uma motivação para a construção deste trabalho.

Através da escassez de obras literárias que envolvessem diretamente o tema, surgiu a necessidade em defender uma maior visibilidade ao assunto em destaque e poder contribuir com estudos e trabalhos futuros no campo da Saúde da Mulher, propagar mais informações e a produção de conhecimentos acerca do aleitamento materno e sua problemática, o desmame precoce e a influência tipo de parto.

A exclusão de certos artigos se deu através de dois critérios: estava em língua estrangeira ou não se encaixava nos fatores envolvidos ao tema abordado. Por isso a análise dos artigos encontrados, a princípio, não envolvia apenas a leitura de títulos e resumos, como da Introdução também, para que o objetivo de tais artigos fosse percebido de maneira mais efetiva.

Em seguida, a partir das 10 obras selecionadas para uma leitura analítica, a análise de conteúdo foi iniciada, avaliando dados e informações. Em seguida, a discussão foi sendo construída e os resultados apresentados, levando em consideração o objetivo central deste trabalho que é discutir sobre a influência do tipo de parto e sua relação com o desmame precoce.

\section{Resultados e Discussão}

A partir da busca nas bases de dados foi feita uma análise e interpretação do material encontrado. A discussão foi construída a partir da apresentação de assuntos que envolveram o aleitamento materno, para que assim, o objetivo geral do tema abordado fosse desenvolvido.

\section{O Aleitamento Materno Exclusivo (AME)}

O leite materno é o alimento ideal para a proteção do recém-nascido contra inúmeras doenças por conta de suaspropriedadesnutricionaiseimunológicas, auxiliando seu crescimento, desenvolvimento saudável e a redução do índice de mortalidade infantil, caracterizando uma forma segura e econômica de alimentação. ${ }^{4}$

O AME proporciona um impacto positivo sobre a saúde e o desenvolvimento e crescimento do bebê, e ainda, do fortalecimento de seu vínculo afetivo com a mãe, fornecendo proteção, nutrição e vantagens imunológicas à criança, contribuindo para a redução da morbimortalidade infantil. ${ }^{3}$

A OMS e o Ministério da Saúde aconselham a amamentação em até dois a três anos de idade da criança, que é o momento em que o desmame pode ocorrer de 
maneira natural. Como o AME é instituído até os seis meses de idade, a OMS aponta que não há benefícios em se iniciar os alimentos complementares antes dessa fase $^{1}$, podendo ainda, resultar em diversos danos à saúde da criança, afinal, incorporar precocemente outros tipos de alimentos pode acarretar certos problemas, tais como:

-Maior índice de quadros de diarreia;

-Aumento de hospitalizações por doença respiratória;

-Grandes chances de desnutrição, pois os alimentos introduzidos podem ser nutricionalmente inferiores ao leite materno;

-Duração menor do aleitamento materno;

-Menor absorção de nutrientes importantes do leite materno, como o ferro e o zinco.

É indicado que após os seis meses de vida do bebê, a amamentação seja mantida junto com a introdução de alimentos complementares e saudáveis, já que a partir dessa idade, a alimentação é um complementar à energia e outros nutrientes fundamentais para um crescimento saudável e um ótimo desenvolvimento das crianças. ${ }^{3}$

$\mathrm{O}$ aleitamento materno apresenta diversas vantagens tanto para o bebê como para a mãe, algumas são mencionadas: ${ }^{7}$

a) Para a mãe:

-Diminuição do sangramento pós-parto, o que acarreta chances menores da ocorrência de anemias;

-Chances menores da incidência de câncer de ovário, endométrio e mama;

-Menor ocorrência de fraturas por osteoporose.

-Melhor homeostase da glicose em mulheres que amamentam, promovendo proteção contra diabetes para ela e para o bebê.

b) Para a Criança:

-Índice de mortalidade reduzido na infância;

-Proteção contra certas doenças, comohipertensão, alergias, diabetes, hipercolesterolemia etc.;

-Melhora no desenvolvimento da cognição e crescimento;

-Fortalecimento do vínculo afetivo entre mãe e filho;

-Desenvolvimento da cavidade bucal.

No entanto, mesmo diante da comprovação científica em provar que o leite materno é superior a qualquer outra alimentação para a criança de até seis meses, e embora diversos órgãos nacionais e internacionais se esforcem a apoiar essa causa e delimitar sua importância, o predomínio de aleitamento materno no Brasil, com destaque para a AME, de acordo com alguns autores, ainda é um número considerado baixo. ${ }^{3}$

\section{Leis e Políticas Públicas que Amparam o Aleitamento Materno no Brasil}

A amamentação é vista como uma vertente de grande importância que aborda a saúde da mulher e a proteção à criança. Nessa perspectiva, é essencial levar em conta o grande papel desempenhado pela família como núcleo gerador dessa proteção, oferecendo auxílio, princípios, estímulo e aprendizagem. É importante mencionar ainda, o papel atuante da sociedade ou, em menor escala, da comunidade, que acabam criando projetos que viabilizem a ação. ${ }^{8}$

O Estado, que também é reconhecido como grande elemento atuante, utiliza o Legislativo para regulamentar as normas em prol da amamentação, instituindo direitos de forma completa e universal, definindo políticas públicas de cunho educacional. $\mathrm{O}$ Estado atua na garantia e proteção desse direito, consolidando e reconhecendo o papel da família, e, em conjunto, intensificando a prática à amamentação. ${ }^{8}$

Cabe ressaltar, que a responsabilidade em proporcionar a proteção legal à amamentação se dá diante da conjuntura dessas duas instâncias, família e Estado. E assim, mesmo que a amamentação esteja inserida no campo de cuidado, sobretudo, familiar, outros setores, comunitário e estatal, integram suas forças, seja de ordem do amparo, da assistência, seja de orem legislativa e das políticas públicas. ${ }^{9}$

$\mathrm{O}$ direito à amamentação deve ser entendido pelo Estado-legislador como algo primordial, que tem início na figura materna e com enfoque na proteção aos direitos universais à vida, à alimentação e à saúde da criança. ${ }^{8}$

O Estado acaba desenvolvendo ações de caráter educacional que estão inseridas no setor da saúde, englobando desde a formação médica até o a fase do pré-natal para o auxílio em amamentação, com o intuito em promover assistência e vigilância, contribuindo com mudanças que estão engajadas no conhecimento e comportamento parental através da divulgação de informações. ${ }^{9}$

Cabe salientar, que um dos principais reconhecimentos da Constituição Federal é o direito fundamental à saúde, previsto em seus artigos $6^{\circ}$ e $196^{\circ}$, de cunho integral e universal.10 A CF promoveu ainda, espaço para um ambiente de proteção e emergência dos direitos humanos, como é previsto em seu Art. $5^{\circ}$ : "Todos são iguais perante a lei, sem distinção de qualquer natureza, garantindo-se aos brasileiros e aos estrangeiros residentes no País a inviolabilidade do direito à vida, à liberdade, à igualdade, à segurança e à propriedade $[\ldots . .]^{\prime} .{ }^{10}$

Em se tratando do direito à amamentação para a criança e a mulher em situação de cárcere, a CF foi a primeira a garantir explicitamente esse direito, como 
é apontado no Art. 50, inciso L: “Às presidiárias serão asseguradas condições para que possam permanecer com seus filhos durante o período de amamentação". ${ }^{10}$

Nessa perspectiva, cabe apontar também, a garantia de direitos à amamentação instituídos às mulheres trabalhadoras, que são previstos pela CLT Consolidação de Leis de Trabalho, mais especificamente em seu Art. 396:

Art. 396. Para amamentar o próprio filho, até que este complete 6 (seis) meses de idade, a mulher terá direito, durante a jornada de trabalho, a 2 (dois) descansos especiais, de meia hora cada um. $\S 1^{\circ}$ Quando o exigir a saúde do filho, o período de 6 (seis) meses poderá serdilatado, a critério da autoridade competente. $\S 2^{\circ}$ Os horários dos descansos previstos no caput deste artigo deverão ser definidos em acordo individual entre a mulher e o empregador. ${ }^{11}$

Foi garantido também o direito à amamentação em locais públicos na cidade do Rio de Janeiro - a Lei $\mathrm{N}^{\circ}$ 7115 , de 24/11/2015, sancionada pelo então governador Luiz Fernando Pezão, que dispõe sobre o direito ao aleitamento materno no Estado do Rio de Janeiro e dá outras providências. Como é apontado:

\begin{abstract}
Art. $1^{\circ}$ Toda criança tem direito ao aleitamento materno, como recomenda a Organização Mundial da Saúde - OMS. Art. $2^{\circ} \mathrm{O}$ estabelecimento situado no Estado do Rio de Janeiro, que proibir ou constranger o ato da amamentação em suas instalações, está sujeito à multa. Parágrafo único. Independente da existência de áreas segregadas para o aleitamento, a amamentação é ato livre e discricionário entre mãe e filho e poderá ocorrer em qualquer local, mesmo onde seja proibido o consumo de alimentos. ${ }^{12}$
\end{abstract}

Em se tratando do Estatuto da Criança e do Adolescente (ECA), este por sua vez, delimita diversos aspectos que envolvem a amamentação, destacando-se o Art. 9:13

Art. 9 O poder público, as instituições e os empregadores propiciarão condições adequadas ao aleitamento materno, inclusive aos filhos de mães submetidas a medida privativa de liberdade. $\S 1$ o Os profissionais das unidades primárias de saúde desenvolverão ações sistemáticas, individuais ou coletivas, visando ao planejamento, à implementação e à avaliação de ações de promoção, proteção e apoio ao aleitamento materno e à alimentação complementar saudável, de forma contínua. $\S 20$ Os serviços de unidades de terapia intensiva neonatal deverão dispor de banco de leite humano ou unidade de coleta de leite humano ${ }^{13}$

Por tudo isso, infere-se, que a composição do direito à amamentação é um desdobramento do direito à saúde, que se reflete como competência legal de proteção e promoção à amamentação, conferindo os direitos à mãe trabalhadora, o direito à alimentação e à saúde da criança. A partir disso, foi constatado que o Brasil possui uma proteção legal amplo em relação à amamentação e uma política fortalecedora nesse âmbito. ${ }^{9}$

Sendo assim, é importante que aconteça um esforço mútuo entre as três instâncias, família, sociedade e Estado, em prol não apenas da elaboração de normatização para proteção e adequação à prática da amamentação como também de políticas educacionais instaladas nas comunidades, procurando levar informações e conhecimentos específicos e práticos sobre a real importância da amamentação, que o leite materno é primordial para o bebê, contribuindo com o seu desenvolvimento de forma saudável e fortalecendo seu vínculo afetivo com a mãe ${ }^{8}$

Nesse contexto, é de grande relevância que as mães recebam total apoio familiar, com o intuito em incentivar a amamentação desde o pré-natal, envolvendose em atividades educativas sobre a importância do aleitamento materno, influenciando a proteção e defendendo um maior tempo de amamentação. ${ }^{14}$

\section{A Influência do tipo de parto sobre o desmame precoce}

Diante da análise e interpretação dos dados a partir dos artigos selecionados, foi possível perceber um índice ainda elevado de desmame precoce no país, mesmo diante da proteção legal abrangente em prol da amamentação no Brasil e por todo o esforço da disseminação de campanhas e ações educativas sobre a importância do aleitamento materno exclusivo até os seis meses de idade da criança pelo poder público e diversas outras instâncias.

Mesmo que o aleitamento materno exclusivo seja o alimento primordial para o bebê até os seis primeiros meses de vida, diversos fatores podem estimular o desmame precoce, como o contexto social no qual a nutriz está inserida, o uso indevido da chupeta, complicações mamárias, como relatos frequentes das mulheres com dores e desconforto, traumas, ingurgitamento mamário e cansaço na prática da amamentação, a falta de leite, rejeição do bebê ao peito, entre outros, ${ }^{14,15}$ além do tipo de parto, que será o fator escolhido como foco da discussão deste trabalho.

Como a OMS estabelece, e diante de todos os estudos selecionados e analisados, foi apontado que o leite materno é o alimento principal para o bebê até os seis meses de idade, sem a complementação de nenhum outro tipo de alimento, e a amamentação deve ser realizada na primeira hora de vida do bebê. O leite materno contém os nutrientes necessários para o crescimento e desenvolvimento da criança, além de fortalecer o vínculo afetivo entre mãe e filho. ${ }^{1}$

No entanto, a prática da amamentação, bem como seu tempo de duração pode sofrer estímulos multifatoriais, como complicações relacionadas à assistência ao parto, como os nascidos de parto cesáreo, 
baixo peso ao nascer, deficiência de orientação ao aleitamento no hospital e cuidados prestados ao recémnascido, promovendo o aumento da incidência do desmame precoce ${ }^{4,14,15}$, como é apontado no estudo realizado por Vieira e seus colaboradores. ${ }^{4}$

O parto normal é capaz de fortalecer o vínculo afetivo entre mãe e filho, promovendo a excreta de leite, condição favorável para a amamentação. A cesárea, por sua vez, determina um tempo maior para o contato afetivo, acarretando no início tardio da amamentação e a consequente interrupção precoce do aleitamento materno, referente à incisão e os efeitos da anestesia no pós-parto. ${ }^{4}$

Diante disso, a cesárea foi identificada como o fator de risco que envolve maior influência ao início tardio da amamentação, reduzindo pela metade a prevalência da amamentação na primeira hora de vida, por conta da anestesia e das rotinas de cuidados pós-operatórios que contribuem com o contato tardio entre mãe e filho. Em virtude disso, pode gerar como consequência, na maioria dos casos, o desmame precoce. ${ }^{4}$

Nessa perspectiva, é possível destacar ainda, que fatores comportamentais também detêm grande estímulo nessa relação, levando em conta que uma nutriz submetida ao parto cesariano, teria predisposição mais reduzida para amamentar. ${ }^{4} \mathrm{O}$ nascimento por parto normal por sua vez, pode contribuir significativamente para a efetivação do aleitamento materno, por ser um método que não promove obstáculos à amamentação na primeira hora de vida, como é o caso da cesárea. ${ }^{4}$

No entanto, é importante ressaltar aqui, que o parto cesariano não deve ser encarado como uma contraindicação à amamentação na sala de parto, afinal, o aleitamento materno propicia importantes benefícios tanto para o bebê como para a mãe, como a produção de ocitocina, capaz de reduzir o sangramento puerperal e acelerar a involução uterina. ${ }^{4}$

No início da amamentação, na primeira hora de vida, o parto cesáreo se manifesta como um empecilho, pelo fato de necessitar dos cuidados pós-operatórios o que pode interferir e aumentar o tempo para iniciar o primeiro contato entre mãe e filho.

Por tudo isso, infere-se, que os fatores associados ao tempo de duração da amamentação são multifatoriais, e de natureza complexa, que em virtude dos partos hospitalares, o início da amamentação ao nascimento seria fortemente dependente das práticas instituídas pela maternidade.

\section{Considerações Finais}

Depreende-se, portanto, que a partir da análise do material encontrado nas bases de dados mencionadas, e todo aparato metodológico, foi possível identificar o tipo de parto como um dos fatores que influenciam o desmame precoce, principalmente o parto cesariano.

Aponta-se, que através do parto normal, o vínculo afetivo entre mãe e filho é fortalecido, favorecendo a excreta de leite, beneficiando, dessa forma, a amamentação. A cesárea, entretanto, define um tempo maior para o contato afetivo, resultando no início tardio da amamentação, o que corrobora com a interrupção precoce do aleitamento materno por conta da incisão e os efeitos da anestesia no pós-parto, reduzindo pela metade a prevalência da amamentação na primeira hora de vida. Nesse contexto, a probabilidade na maioria dos casos, de ocorrer o desmame precoce é extremamente alta.

Sendo assim, o trabalho em questão foi de grande relevância para que essa condição fosse melhor estudada, e, mesmo que a quantidade de material encontrado sobre o tema escolhido tenha sido pouco significativa, o essencial foi discutido, a influência do tipo de parto sobre o desmame precoce e suas consequências, o que garante um marco inicial para estudos mais aprofundados sobre o tema posteriormente.

\section{Referências}

1. Br. Brasil. Ministério da Saúde Secretaria de Políticas de Saúde. Saúde da Criança, Aleitamento Materno e Alimentação Complementar. Caderno de atenção básica, 2. Ed.; n. 23. Brasília, 2015.

2. Barbieri $\mathrm{CM}$ et al. Aleitamento materno: orientações recebidas no prénatal, parto e puerpério. Semina: Ciências Biológicas e da Saúde, 2015; 36(1):17-24

3. Lima VF. A importância do aleitamento materno: Uma revisão de literatura. (Trabalho de Conclusão de Curso). João Pessoa/PB, 2017.

4. Vieira FS, Costa ES, Sousa, GC et al. Influência do Parto Sobre o Desmame no Puerpério. Rev Fund Care Online. 2019. 11(n. esp):425-431. DOI: http:// dx.doi.org/10.9789/2175-5361.2019.v11i2.425-431.

5. Alvarenga SC, Castro DS, Leite FMC et al. Fatores que influenciam o desmame precoce. Rev. Aquichan, 2017; 17(1): 93-103.

6. Oliveira CS, Locca FA, Carrijo MR, Garcia RATM. Amamentação e as intercorrências que contribuem para o desmame precoce. Rev Gaúcha Enferm., 2015; 36(esp.): 16-2.

7. Caputo Neto M. Caderno de Atenção à Saúde da Criança: Aleitamento Materno. Secretaria de Estado da Saúde. Banco de Leite Humano de Londrina. IBFAN Brasil. Sociedade Paranaense de Pediatria. Paraná, 2013. Disponível em: http://www.saude.pr.gov.br/arquivos/File/pdf3.pdf. Acesso em: 5 jun. 2020 .

8. Neves, MCA. Revista dos Tribunais. RT VOL. 967 (MAIO 2016). Direito Constitucional. Amamentação - Um direito que ultrapassa os limites da lei.

9. Lima IMSO, Leão TM, Alcântara MAR. Proteção legal à amamentação, na perspectiva da responsabilidade da família e do Estado no Brasil. R. Dir. sanit., São Paulo, v. 14, n. 3, p. 66-90, nov. 2013/ fev. 2014.

10. Brasil. Constituição da República Federativa do Brasil de 1988. Disponível em: http://www.planalto.gov.br/ccivil_03/constituicao/constituicao.htm Acesso em: 13 mar. 2020.

11. Brasil. Decreto-Lei № 5.452 , de $1^{\circ}$ de maio de 1943 . Consolidação das Leis do Trabalho. Disponível em: http://www.planalto.gov.br/ccivil 03/ decreto-lei/del5452.htm. Acesso em: 13 mar. 2020.

12. Alerj. Lei $\mathrm{N}^{\mathrm{o}} 7115$ de $24 / 11 / 2015$. Dispõe sobre o direito ao aleitamento materno no Estado do Rio de Janeiro e dá outras providências. Disponível em: http://alerjln1.alerj.rj.gov.br/CONTLEI.NSF/b24a2da5a077847c032564 f4005d4bf2/65a08e2d4384e05083257f0a005cb28a?OpenDocument. Acesso 
em: 5 jun. 2020.

13. Brasil. Lei $\mathrm{N}^{\circ} 8.069$, de 13 de Julho de 1990. Dispõe sobre o Estatuto da Criança e do Adolescente e dá outras providências. Disponível em: http:// www.planalto.gov.br/ccivil_03/leis/18069.htm . Acesso em: 5 jun. 2020.

14. Vasconcelos, TC; Barbosa, DJ; Gomes, MP. Fatores que interferem no aleitamento materno exclusivo durante os primeiros seis meses de vida do bebê. Revista Pró-UniverSUS. 2020 Jan./Jun.; 11 (1): 80- 87.

15. Sousa MS, Aquino PS, Aquino CBQ, Penha JC, Pinheiro AKB.

Aleitamento materno e os determinantes do desmame precoce. Rev. Enferm. UFPI, 4(1):19-25, jan./mar. 2015. 